\title{
Conservation Agriculture in mixed crop-livestock systems: Scoping crop residue trade-offs in Sub-Saharan Africa and South Asia
}

\author{
Diego Valbuena $^{\mathrm{a}, *}$, Olaf Erenstein ${ }^{\mathrm{b}}$, Sabine Homann-Kee Tui ${ }^{\mathrm{c}}$, Tahirou Abdoulaye ${ }^{\mathrm{d}}$, \\ Lieven Claessens $^{\mathrm{e}, \mathrm{f}, \mathrm{j}}$, Alan J. Duncan ${ }^{\mathrm{g}}$, Bruno Gérard ${ }^{\mathrm{a}, \mathrm{b}}$, Mariana C. Rufino ${ }^{\mathrm{h}}$, Nils Teufel ${ }^{\mathrm{i}}$, \\ André van Rooyen ${ }^{\mathrm{c}}$, Mark T. van Wijk ${ }^{\mathrm{h}, \mathrm{j}}$ \\ a Systemwide Livestock Programme, Addis Ababa, Ethiopia \\ b CIMMYT, Addis Ababa, Ethiopia \\ c ICRISAT, Bulawayo, Zimbabwe \\ d IITA, Ibadan, Nigeria \\ e CIP, Nairobi, Kenya \\ ${ }^{\mathrm{f}}$ ICRISAT, Nairobi, Kenya \\ ILRI, Addis Ababa, Ethiopia \\ h ILRI, Nairobi, Kenya \\ i ILRI, New-Delhi, India \\ ${ }^{\mathrm{j}}$ Wageningen University, Wageningen, The Netherlands
}

\section{A R T I C L E I N F O}

\section{Article history:}

Received 14 June 2011

Received in revised form

22 December 2011

Accepted 22 February 2012

\section{Keywords:}

Biomass use

Mulching

Feed

Sustainability

Intensification

Human population density

Livestock density

\begin{abstract}
A B S T R A T
Conservation Agriculture (CA) is being advocated to enhance soil health and sustain long term crop productivity in the developing world. One of CA's key principles is the maintenance of soil cover often by retaining a proportion of crop residues on the field as mulch. Yet smallholder crop-livestock systems across Africa and Asia face trade-offs among various options for crop residue use. Knowledge of the potential trade-offs of leaving more residues as mulch is only partial and the objective of this research is to address some of these knowledge gaps by assessing the trade-offs in contrasting settings with mixed crop-livestock systems. The paper draws from village surveys in 12 sites in 9 different countries across Sub-Sahara Africa and South Asia. Sites were clustered into 3 groups along the combined population and livestock density gradients to assess current crop residue management practices and explore potential challenges to adopting mulching practices in different circumstances. Results show that although highdensity sites face higher potential pressure on resources on an area basis, biomass production tends to be more substantial in these sites covering demands for livestock feed and allowing part of the residues to be used as mulch. In medium-density sites, although population and livestock densities are relatively lower, biomass is scarce and pressure on land and feed are high, increasing the pressure on crop residues and their opportunity cost as mulch. In low-density areas, population and livestock densities are relatively low and communal feed and fuel resources exist, resulting in lower potential pressure on residues on an area basis. Yet, biomass production is low and farmers largely rely on crop residues to feed livestock during the long dry season, implying substantial opportunity costs to their use as mulch. Despite its potential benefit for smallholder farmers across the density gradient, the introduction of CA-based mulching practices appears potentially easier in sites where biomass production is high enough to fulfil existing demands for feed and fuel. In sites with relatively high feed and fuel pressure, the eventual introduction of CA needs complementary research and development efforts to increase biomass production and/or develop alternative sources to alleviate the opportunity costs of leaving some crop residues as mulch.
\end{abstract}

(c) 2012 Elsevier B.V. All rights reserved.

\footnotetext{
* Corresponding author.

E-mail address: d.valbuena@cgiar.org (D. Valbuena).
}

\section{Introduction}

Conservation Agriculture (CA) is being advocated over conventional agriculture so as to enhance soil health and sustain long term crop productivity (Govaerts et al., 2009; Hobbs et al., 2008). CA revolves around three main principles: minimum soil disturbance; permanent soil cover, primarily by retaining crop 
residues as mulch; and crop rotation, especially with legumes (FAO, 2009). Although there has been a rapid uptake of CA, it tends to be concentrated amongst relatively large-scale farmers located in North America, South America, Australia and New Zealand and these account for an estimated 95\% of the world area currently using CA practices (Kassam et al., 2010). Proponents argue that the potential benefits of CA can be equally extended to Africa and Asia (FAO, 2009; Wall, 2007), regions largely dominated by smallholder farmers, who often combine crop and livestock production in mixed farming systems (McIntire et al., 1992).

In (sub)tropical Africa and Asia, smallholder mixed systems contribute to the livelihood of two-thirds of the population, producing a large part of the staple food and animal products consumed by poor people (Herrero et al., 2010). These systems are characterised by the combination and interdependence of crop production and livestock husbandry. While the crop component of these systems provides feed to the animals, the livestock component provides manure and traction (McIntire and Gryseels, 1987), and is an important saving option and source of cash income enabling farmers to purchase inputs, food and other goods (Christiaensen et al., 1995; Fafchamps et al., 1998; Hoddinott, 2006; Moll, 2005). The crop-livestock combination offers farmers a more diverse source of food and income, reducing risk, diversifying labour use and recycling resources (FAO, 2001a,b). Despite such complementarities, smallholder mixed systems often face numerous challenges and constraints, linked to often limited resources such as land, labour, capital, competing demands and limited access to livelihood enhancement opportunities, including access to information, inputs, technologies and markets. The situation is exacerbated by external factors such as an increasing climate variability, population pressure, environmental degradation and low public/private investment.

The inherent nature of mixed systems often implies competing uses of crop residues since they are not only used as feed but also as mulch/soil amendment, fuel and construction material, both within the mixed farm and/or by others (Erenstein, 2002). Such trade-offs are often dependent on the specific biophysical and socio-economic farming characteristics and context, including factors related to the availability and demand of residues and farmers' preferences (Erenstein et al., 2011). For instance, one would expect such tradeoffs tend to be more pronounced in mixed crop-livestock systems with high pressure on land and feed resources, as well as in poorer regions where farmers cannot afford to invest in alternative biomass-enhancing technologies and have strong priorities on securing immediate food needs. One of CA's key principles is the maintenance of some soil cover throughout the year, primarily by retaining some crop residues on fields as mulch-alternative options such as cover crops imply additional costs and challenges (Erenstein, 2003). Alternative crop residue uses-particularly as livestock feed-thereby tend to represent a major challenge for CA adoption in smallholder mixed systems across the (sub)tropics (FAO, 2009; Giller et al., 2009; Wall, 2007). Still, our knowledge of these potential trade-offs is only partial, not least due to their site specificity in view of the broad range of mixed crop-livestock production systems with different biophysical conditions, policy context and market accessibility (Iiyama et al., 2007a; McIntire et al., 1992). Indeed, a recent review and synthesis of CA flagged the need to undertake comparative studies across different contexts (Knowler and Bradshaw, 2007). The objective of this paper is to contribute to filling some of these knowledge gaps by assessing the potential trade-offs of eventually retaining more crop residues as mulch in contrasting settings with mixed crop-livestock systems. It specifically assesses the diversity of crop residue use/management practices in mixed farming systems in contrasting sites across Sub-Sahara Africa and South Asia. It does so by drawing on a common research approach across regions involving clusters of village surveys (semi-quantitative focus group discussions) in 9 different countries to generate comparative indicators. We hypothesise that human population and livestock densities are key overarching factors influencing the demand, supply and management of crop residues. In other words, similar pressures on land and feed are likely to result in comparable crop residue management practices and thus similar trade-offs in terms of increased residue retention as mulch for CA.

\section{Methods}

This scoping study aimed to cover a range of diverse mixed farming systems in Sub-Sahara Africa and South Asia, including different crop-livestock systems in contrasting agro-ecologies and socio-economic settings. It first stratified the target area into 4 (sub)tropical regions: Eastern Africa, Southern Africa, Western Africa and South Asia. In each sub-region 3 contrasting sites were purposively selected along a relative system intensity gradient (low-medium-high, based on a combination of agro-ecology and agricultural intensification). In each site, one or two main regional markets were selected, around which a set of $4-8$ villages was randomly selected stratifying by distance to the selected markets and major roads. The site selection was primarily based on regional expert knowledge within the regions where participating research centres were based. Being a scoping study it purposively targeted sites with different agro-ecologies, intensification levels and market accessibility and the selected sites are thus not necessarily nationally or regionally representative. To enhance site diversity each sub-region included at least 2 countries. The site selection resulted in 12 sites across 9 countries: Ethiopia and Kenya in Eastern Africa; Malawi, Mozambique and Zimbabwe in Southern Africa; Niger and Nigeria in Western Africa; and Bangladesh and India in South Asia. Table 1 summarizes the main biophysical and socioeconomic characteristics of the 12 research sites.

Quantitative village level surveys were conducted in all villages to better describe and understand the diversity of mixed systems and crop residue management. The village surveys were carried out during 2010 and early 2011 with groups of 10-30 farmers of different age, gender, land and livestock ownership to capture the diversity of farming practices, including main crop residue uses and general information about each local context. A structured questionnaire was developed by a multi-disciplinary team of researchers working in the study regions, including socio-economists, crop and livestock scientists. The questionnaire included 6 parts (i) village location and population; (ii) land use, cultivated area, grasslands and irrigated area; (iii) crop growing seasons, main crops, use of crops and residues; (iv) herd composition, feeding strategies, feed shortages and use of manure; (v) income composition per household wealth classes; and (vi) livelihood indicators such as literacy, access to different services and input/output prices. Many of the questions also included a retrospective component to assess historical trends in farm management and socio-economic conditions. The results of these village level surveys were averaged at the site (village cluster) level to facilitate the description and comparison across research sites.

For analytical purposes we first clustered the research sites into broad population-livestock density clusters along a population and livestock density gradient and subsequently compared various relevant indicators across these clusters. These indicators included selected biophysical and socio-economic factors, including crop and livestock production, to better understand the supply and demand for crop residues. Population density at the site (village cluster) level was estimated as the average number of people living in a village divided by the average village size in hectares (total reported village land, including uncultivated). Similarly, 


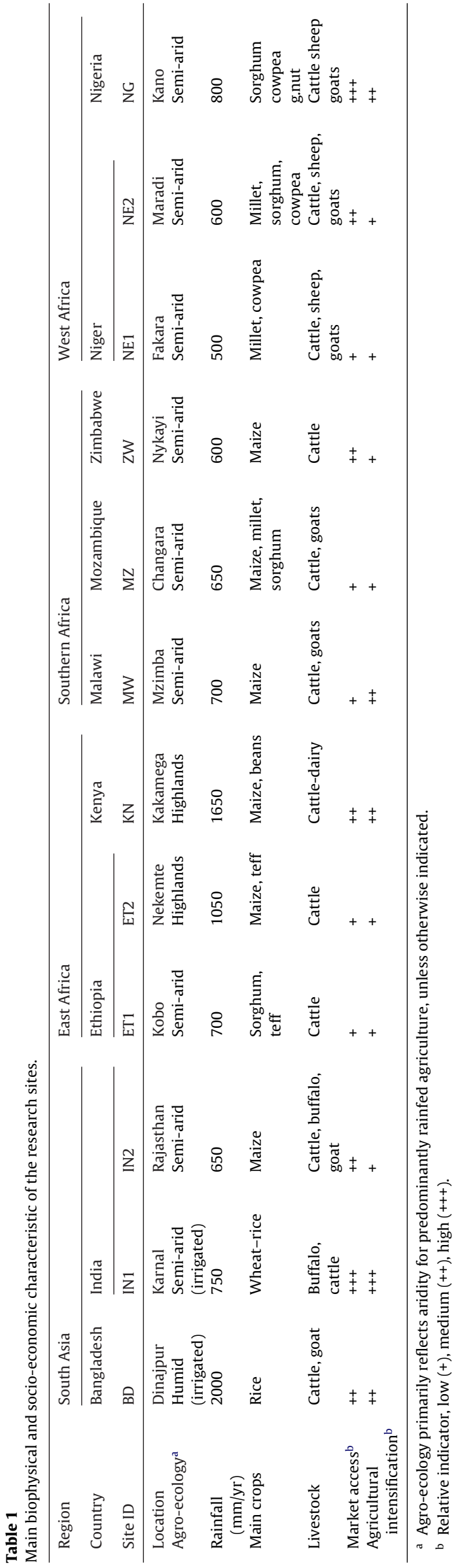

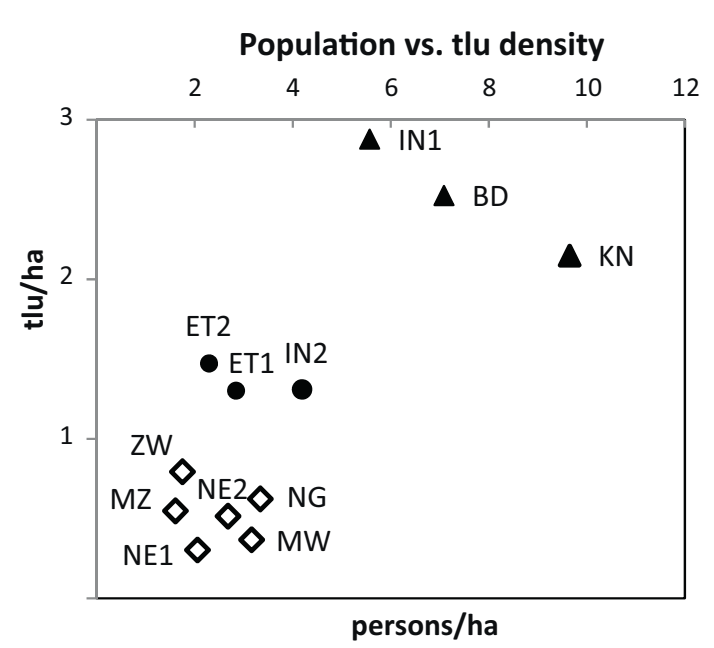

Fig. 1. Contrast of population and livestock density in research sites. Site id: see Table 1 . Triangles represent high-density sites; dots medium-density; and trapezoids low-density.

livestock density at the site level was estimated as the average number of tropical livestock units (TLU) within the village divided by the average village size in hectares. The use of averages at a site level limits the potential influence of extreme density values in specific villages, which might unduly influence the average value calculated for a set of only 8 villages. Based on the population-livestock density clusters, we explore the biophysical and socio-economic context of the farming systems in the research sites. Then, we describe the supply and demand side factors of crop residue management in the different sites and clusters, including a retrospective component.

It is important to reiterate that this is a scoping study where we aim to provide an initial assessment of the diversity and its possible implications. Indeed, although the village level surveys compiled quantitative indicators, these indicators are typically estimates by the group informants and the number of villages in each site is still relatively limited. Such indicators are still useful to illustrate the diversity and relative differences, but are less appropriate for robust statistical analysis. In the present scoping study we will therefore often refer to apparent associations between indicators. Complementary follow up research including household surveys, some of which is already initiated, will allow for a more quantitative analysis.

\section{Results}

\subsection{Population-livestock density clusters and system overview}

To identify relevant population-livestock density clusters the population and livestock density gradients were plotted against each other (Fig. 1). Three main clusters of sites thereby emerged (hereafter referred to as density clusters): (i) a high-density cluster where both population and livestock densities are relatively high, that groups 3 sites-Bangladesh, India- 1 and Kenya (identified by triangles in Fig. 1); (ii) a medium-density cluster, mainly in terms of livestock density, comprising 3 sites-both Ethiopian sites and India-2 (identified by dots); and (iii) a low-density cluster with relative low density of both population and livestock, comprising the remaining 6 sites-including all sites in Southern and Western Africa (identified by trapezoids).

Selected livelihood indicators of the research sites are presented in Table 2. The values of these indicators vary considerably, without any apparent association to density clusters. One might expect an inverse relation between population density and farm size-but the 
Table 2

Livelihood indicators in research sites.

\begin{tabular}{|c|c|c|c|c|c|c|c|c|c|c|c|c|}
\hline \multirow{2}{*}{$\begin{array}{l}\text { Density cluster } \\
\text { Site ID }\end{array}$} & \multicolumn{3}{|c|}{ High density } & \multicolumn{3}{|c|}{ Medium density } & \multicolumn{6}{|c|}{ Low density } \\
\hline & IN1 & $\mathrm{BD}$ & $\mathrm{KN}$ & ET2 & IN2 & $\overline{\text { ET1 }}$ & $\overline{Z W}$ & NG & $\mathrm{MZ}$ & NE2 & MW & NE1 \\
\hline \multicolumn{13}{|l|}{ Densities } \\
\hline Human population (people/ha) & 5.6 & 7.1 & 9.7 & 2.3 & 4.2 & 2.8 & 1.8 & 3.3 & 1.6 & 2.7 & 3.2 & 2.0 \\
\hline Livestock (TLU $\left.{ }^{\mathrm{b}} / \mathrm{ha}\right)$ & 2.9 & 2.5 & 2.1 & 1.5 & 1.3 & 1.3 & 0.8 & 0.6 & 0.5 & 0.5 & 0.4 & 0.3 \\
\hline \multicolumn{13}{|l|}{ Assets (average \#/household) } \\
\hline Farm size (ha) & 1.0 & 0.6 & 0.5 & 1.8 & 0.7 & 1.4 & 2.4 & 2.7 & 1.3 & 2.9 & 1.2 & 5.0 \\
\hline Household size (people) & 6.9 & 5.5 & 5.8 & 5.3 & 5.5 & 5.6 & 8.1 & 8.7 & 6.1 & 11 & 8.3 & 9.2 \\
\hline Livestock (TLU) & 3.3 & 2.0 & 1.1 & 3.3 & 1.7 & 2.5 & 3.7 & 1.6 & 2.2 & 1.5 & 1.0 & 1.4 \\
\hline \multicolumn{13}{|l|}{ Assets \& labour (\% households) } \\
\hline Own land & 51 & 69 & 97 & 93 & 86 & 93 & 98 & 100 & 100 & 89 & 100 & 78 \\
\hline Own livestock & 88 & 88 & 89 & 83 & 79 & 77 & 70 & 99 & 65 & 64 & 49 & 66 \\
\hline Providing agri labour & 55 & 53 & 54 & 10 & 85 & 4 & 46 & 64 & 59 & 75 & 12 & 34 \\
\hline Member out of the village & 15 & 26 & 36 & 6 & 71 & 3 & 34 & 51 & 25 & 52 & 23 & 75 \\
\hline Female headed (\% households) & 5 & 9 & 44 & 16 & 13 & 23 & 38 & 8 & 22 & 21 & 8 & 12 \\
\hline $\begin{array}{l}\text { Food insecure ( } \% \mathrm{hh}^{\mathrm{c}} \text { some-times } \\
\text { having only } 1 \text { meal per day) }\end{array}$ & 4 & 3 & 16 & 0 & 28 & 7 & 7 & 7 & 2 & 31 & 17 & 13 \\
\hline Literacy (\% adults) & 54 & 53 & 58 & 43 & 38 & 39 & 82 & 50 & 56 & 50 & 59 & 38 \\
\hline \multicolumn{13}{|l|}{ Household income (\%) } \\
\hline Agriculture & 48 & 62 & 16 & 85 & 6 & 79 & 58 & 63 & 25 & 79 & 55 & 38 \\
\hline Agricultural labour & 41 & 20 & 50 & 8 & 10 & 4 & 24 & 8 & 33 & 8 & 38 & 29 \\
\hline Off-farm & 11 & 18 & 33 & 6 & 84 & 17 & 18 & 26 & 42 & 13 & 7 & 33 \\
\hline
\end{tabular}

a Site id: see Table 1.

b TLU: tropical livestock unit, equivalent to an animal of $250 \mathrm{~kg}$ weight.

c hh, households.

association appears relatively weak. Smallholder farmers prevail across all sites, with average farm sizes of less than 2 ha, except in Zimbabwe and West African-all low density sites. Similarly, there is no clear association between land ownership and density clusters, albeit that the two sites with highest landlessness (i.e. lowest share of households owning land, Table 2) are both located in the high density cluster as expected. Reflecting our focus on mixed smallholders, at least half the village households owned land and at least half households owned livestock. These two shares are substantially higher for most of the sites though (Table 2), with the high-density India-1 site standing out due to half its households being landless and the low-density Malawi site for half the households not having livestock. In most sites a substantial share of households provide agricultural labour and/or have a member working outside the village, although this is less common for the medium-density sites in Ethiopia. The research sites are still primarily agricultural, with over half of the reported average household income coming from agriculture and agricultural labour-the only exception being India-2 with a heavy reliance on off-farm income. Female-headed households were relatively common in Kenya and Zimbabwe. Overall though the rural communities in the research sites were relatively poor and had limited human capital, reflected by a number of households being food insecure (only able to eat 1 meal per day during part of the year) and relatively low levels of adult literacy (typically 38-59\%, albeit higher in Zimbabwe).

\subsection{Crop-livestock production}

Crop production in the research sites is typically dominated by cereal production with a varying role for legumes and other crops (Table 3). Cereals encompass both fine grains (primarily in the high-medium density areas, including rice, wheat, teff) and coarse grains (particularly in the medium-low density areas, including maize, sorghum, millet-Table 1). Legumes (including cowpea, beans, groundnut) are commonly present and intercropped in low-density sites, as well as in high-density Kenya where farmers intercrop maize with beans. Other crops are varied, including tubers and sugar cane in Kenya; and tubers and tobacco in Malawi.

Various crop production indicators appear to be associated with the density clusters (Table 3 ). Most obvious are indicators associated with agricultural seasons and land use intensity. The high-density sites all have two or three main cropping seasons per year, have a long cumulative annual growing season (9-10 months per annum) enabled by high crop water availability (irrigation access and/or high rainfall) and high agricultural land use intensities (Table 3). The medium- and low-density sites all have only one main cropping season, have a short annual growing season (typically 6 or less months per annum) constrained by crop water availability and have relatively low agricultural land use intensities (Table 3). For instance, in low density sites in Southern Africa fallowing and communal grassland are common, resulting in relatively limited cropped areas.

In line with expectations, crop intensification appears positively associated with the density clusters (Table 3). Market-oriented smallholder crop production is largely limited to the high-density cluster in South Asia, with smallholders elsewhere typically having a dual purpose orientation of meeting home consumption needs and marketing of surplus. Chemical fertilizer use is particularly widespread in the high density cluster. Only Nigeria and Malawi reach similar penetration of fertilizer use. In Nigeria this reflects market access with widespread use but generally low fertilizer rates; in Malawi it is associated with the government fertilizer subsidy program and contributing to its relatively higher share of crop produce being sold (albeit still less than half). Tractor tillage is largely limited to high-density sites in South Asia, with animal traction being commonly practiced elsewhere except in Malawi and Niger-1 sites where hand tillage still prevails. Hand weeding is dominant in all sites, excluding India- 1 where herbicide use is widespread.

Livestock production in the research sites is typically dominated by large ruminants except in Nigeria where small ruminants prevail (Table 4). Dairy animals appear to be positively associated with the density clusters (Table 4). Other large ruminants include cattle for meat and draft. Small ruminants tend to be more important in the herd composition of low-density sites, excluding Zimbabwe (Table 4). Access to grasslands was extremely constrained in the high-density sites in South Asia, but typically showed a marked increase proceeding to medium- and on to the low-density cluster.

There was a marked diversity in the reported feed composition across sites, of which only some appeared to be associated with 
Table 3

Characteristics of crop production in research sites.

\begin{tabular}{|c|c|c|c|c|c|c|c|c|c|c|c|c|}
\hline \multirow{2}{*}{$\begin{array}{l}\text { Density cluster } \\
\text { Site ID }\end{array}$} & \multicolumn{3}{|c|}{ High density } & \multicolumn{3}{|c|}{ Medium density } & \multicolumn{6}{|c|}{ Low density } \\
\hline & IN1 & $\mathrm{BD}$ & $\mathrm{KN}$ & ET2 & IN2 & ET1 & ZW & NG & $\mathrm{MZ}$ & NE2 & MW & NE1 \\
\hline \multicolumn{13}{|l|}{ Crop areas (\% cultivated area) } \\
\hline Cereals & 88 & 81 & 36 & 84 & 88 & 96 & 82 & 65 & 67 & 72 & 59 & 58 \\
\hline Legumes & 4 & 1 & 37 & 2 & 3 & 3 & 13 & 27 & 27 & 17 & 14 & 38 \\
\hline Other & 8 & 19 & 27 & 14 & 9 & 2 & 5 & 8 & 5 & 11 & 27 & 4 \\
\hline \multicolumn{13}{|l|}{ Growing season } \\
\hline No. per year & $2^{\mathrm{b}}$ & 3 & 3 & 1 & 1 & 1 & 1 & 1 & 1 & 1 & 1 & 1 \\
\hline Duration (months pa) ${ }^{c}$ & 10.3 & 10.2 & 8.8 & 5.1 & 4.5 & 4.0 & 6.3 & 4.4 & 6.0 & 4.7 & 6.3 & 4.2 \\
\hline \multicolumn{13}{|l|}{ Ag. land use intensity } \\
\hline (\% area cultivated pa) & 179 & 203 & 216 & 77 & 66 & 78 & 39 & 96 & 25 & 101 & 36 & 87 \\
\hline \multicolumn{13}{|l|}{ Market orientation } \\
\hline (\% produce sold main 3 crops) & 77 & 70 & 28 & 38 & 3 & 34 & 16 & 26 & 8 & 20 & 46 & 31 \\
\hline \multicolumn{13}{|l|}{ Agricultural inputs (\% area) } \\
\hline Irrigated & 84 & 74 & 0 & 2 & 6 & 1 & 0 & 4 & 1 & 0 & 2 & 0 \\
\hline Use manure & 51 & 95 & 54 & 22 & 65 & 8 & 28 & 100 & 15 & 73 & 38 & 53 \\
\hline Use fertilizer & 100 & 100 & 79 & 73 & 59 & 1 & 16 & 100 & 0 & 64 & 93 & 45 \\
\hline Use herbicides & 84 & 32 & 2 & 51 & 1 & 34 & 0 & 1 & 0 & 4 & 1 & 0 \\
\hline \multicolumn{13}{|l|}{ Mechanisation tillage (\% area $)^{\mathrm{d}}$} \\
\hline By tractor & 100 & 92 & 13 & 0 & 26 & 6 & 0 & 3 & 0 & 4 & 0 & 0 \\
\hline By animal & 0 & 11 & 64 & 100 & 66 & 99 & 96 & 61 & 59 & 74 & 27 & 0 \\
\hline Hand weeding (\% area) & 50 & 100 & 98 & 98 & 99 & 100 & 100 & 98 & 100 & 100 & 99 & 88 \\
\hline
\end{tabular}

a Site id: see Table 1 .

b A third season exists, but not actively used.

c pa: per annum.

d Combinations of tractor, animal and manual tillage are possible, so does not necessarily sum to $100 \%$.

Table 4

Characteristics of livestock production in research sites.

\begin{tabular}{|c|c|c|c|c|c|c|c|c|c|c|c|c|}
\hline \multirow{2}{*}{$\begin{array}{l}\text { Density cluster } \\
\text { Site ID }\end{array}$} & \multicolumn{3}{|c|}{ High density } & \multicolumn{3}{|c|}{ Medium density } & \multicolumn{6}{|c|}{ Low density } \\
\hline & IN1 & $\mathrm{BD}$ & KN & ET2 & IN2 & ET1 & ZW & NG & $\mathrm{MZ}$ & NE2 & MW & NE1 \\
\hline \multicolumn{13}{|l|}{ Livestock production } \\
\hline Share large ruminants (\% TLU) $)^{b}$ & 98 & 82 & 91 & 90 & 89 & 88 & 79 & 12 & 72 & 59 & 68 & 80 \\
\hline Share small ruminants (\% TLU) & 1 & 12 & 2 & 4 & 10 & 4 & 6 & 63 & 18 & 34 & 15 & 15 \\
\hline Share other stock ${ }^{\mathrm{c}}$ (\% TLU) & 1 & 6 & 7 & 6 & 1 & 8 & 15 & 25 & 10 & 7 & 17 & 5 \\
\hline$\%$ households with dairy animals & 85 & 63 & 62 & 71 & 56 & 60 & 49 & 17 & 51 & 48 & 39 & 34 \\
\hline$\%$ households with access to grassland & 13 & 13 & 95 & 87 & 88 & 57 & 100 & 88 & 100 & 88 & 100 & 68 \\
\hline \multicolumn{13}{|l|}{ Shortages of feed (months/yr) } \\
\hline Crop residues & 2.1 & 3.1 & 8.5 & 7.3 & 8.4 & 5.9 & 4.5 & 5.5 & 4.8 & 6.5 & 1.2 & 7.8 \\
\hline Green fodder & 2.5 & 3.6 & 5.3 & 6.0 & 8.4 & 7.0 & n.a. & 7.3 & n.a. & 8.0 & n.a. & 7.9 \\
\hline Grazing & n.a. & 5.3 & 5.8 & 6.8 & 7.0 & 9.4 & 5.8 & 5.6 & 5.6 & 6.0 & 4.9 & 6.3 \\
\hline
\end{tabular}

Note: n.a.: not applicable.

a Site id: see Table 1 .

b TLU: tropical livestock unit.

c Other stock includes horses, donkeys, camels and poultry.

the density clusters (Fig. 2). Taken together, the contribution of crop residues and green fodder declined from high-density to lowdensity clusters, whereas the contribution of grazing increased. The share of concentrates was relatively limited across all sites.

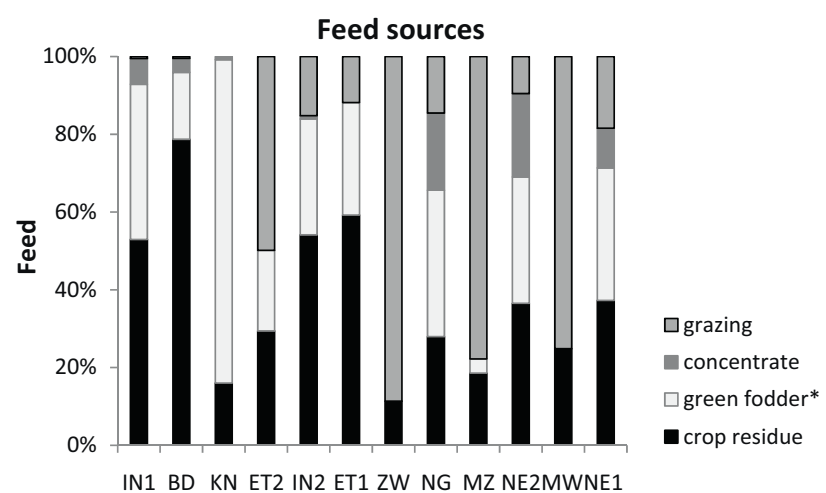

Fig. 2. Reported livestock feed composition in research sites. Note: *includes fodder crops, cut \& carry leaves/grass, and green crop by-products.
The relative contribution of crop residues and green fodder to the overall diet showed substantial variation. For instance in highdensity sites where the share of grazing was relatively negligible, all households used crop residues, but green fodder provided a limited complementary share in Bangladesh and the major share in Kenya (e.g. Napier grass). In medium-density sites, feed was a mix of crop residues, green fodder and grazing. In low-density sites in Southern Africa, grazing was the major feed source for livestock, complemented with crop residues in the driest part of the year. In low-density sites in West Africa, where considerable livestock markets exist, communal land has drastically shrunk or highly degraded limiting grazing and promoting green fodder and to a lesser extent concentrates (i.e. bran) as alternative feed. Despite their high population and livestock densities, high-density sites in South Asia reported relatively limited feed shortages (Table 4), reflecting the ready availability of residues and green fodders, complemented with concentrates, substituting for the lack of grazing land. Particularly in India-1, around $87 \%$ of farmers used mechanical cutters (or choppers) to improve the intake of crop residues by livestock. In medium-density sites and low-density sites in West Africa, farmers reported the most prolonged shortages of feed resources over the course of the year (Table 4), while in low-density sites in 


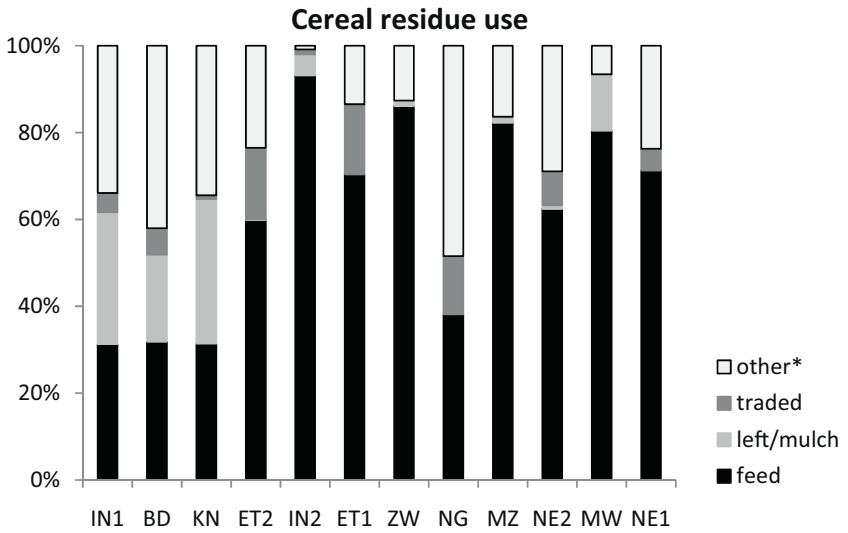

Fig. 3. Reported cereal residue use in research sites. Note: Reported \% share of cereal residues produced. "Other" use includes use as fuel, construction and burnt.

Southern Africa the duration of feed shortages was intermediate. Malawi, one of the low-density sites, stood out for its limited duration of residue scarcity to feed livestock, linked to relatively limited livestock numbers.

\subsection{Crop residue management}

There was a marked diversity in crop residue management practices across sites, which for the purposes of this study have been broadly grouped into use as feed, left in the field (as mulch or incorporated), traded and used for other purposes (including use as fuel, construction and burnt-Fig. 3). The variety is perhaps not surprising given the diversity of sites and the associated richness in crop and livestock production practices and the population and livestock density-gradients. Still, across this diversity of mixed farming systems, cereal residue use as livestock feed remains a prevailing use, including in low-density sites with limited livestock such as Malawi (Fig. 3). In high-density sites about a third of the cereal residues were used as feed, with higher shares in the mediumand low-density sites, even surpassing $80 \%$ in sites such as India- 2 and Southern Africa. Sites in which a substantial share of "surplus" cereal residues were left in the field $(>20 \%)$ were largely limited to the high-density cluster, including wheat and rice straw in Bangladesh and India-1 respectively, and maize stover in Kenya. Low-density Malawi again was the exception, with around $15 \%$ of the maize and millet stover being reportedly left in the fields. Substantial trading of cereal residues was found in high-density India-1 (wheat straw), medium-density Ethiopia-2 (teff straw) and West African sites (millet and sorghum stover), often for off-farm feed use. A substantial share of cereal residues were also reportedly used for fuel or construction in most sites, including India-1, Bangladesh, Kenya, Ethiopia and West Africa.

Legume residues are often managed differently from cereal residues, not least because they typically have higher feed value. Yet in view of the prevalence of cereals in the cropping patterns of the research sites the available data collected for legumes are relatively limited and do not allow for a detailed analysis. However, in the sites in West Africa legume residues are often fed and traded, whereas they are mostly used for cooking purposes in high-density Kenya (Table 5).

In the last decade, increasing pressure on land and feed resources have influenced the crop residue management across all sites. The use of crop residues for stall feeding and stubble grazing have increased in most sites (Table 5), reflecting a mounting demand for crop residues as livestock feed. Five sites reported increases in residue trading. Consequently, the amount of residues left in the field has decreased in some sites, particularly in Kenya
Residue as feed vs. tlu density

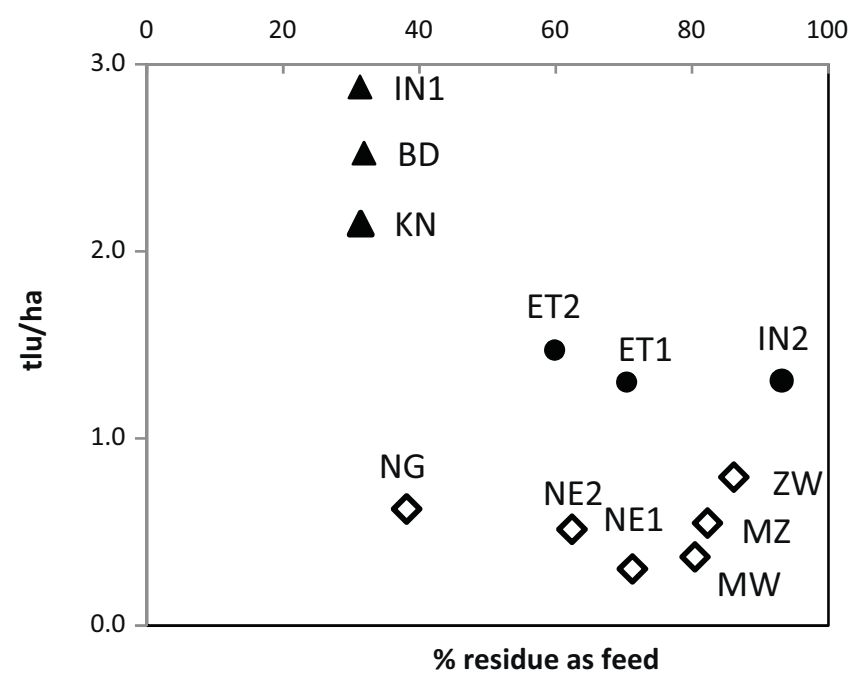

Fig. 4. Relationship between the share of cereal residues used as feed and livestock density in research sites. Note: Triangles represent high-density sites; dots mediumdensity; and trapezoids low-density.

and Ethiopia because of the increasing demand on feed resources, and increased in others. Both the high-density sites in South Asia reported such increases, linked inter alia to increasing mechanization (i.e. combine harvester). However, even in the low-density cluster such increases have been reported. In Zimbabwe, farmers argue that lack of labour and transport has limited the collection of residues after harvesting; whereas in Malawi farmers mentioned an increase in the use of mulching to improve the soil properties over the last years. The use of crop residues as fuel has reportedly increased in some sites as a result of the lack of alternative fuel sources such as firewood.

The increasing use of crop residues for purposes other than mulching implies that these have become a private good with an explicit economic value. Residues are indeed privately owned in the high-density sites and in medium-density India-2, whereas they are often still regarded as public or semi-public elsewhere (Table 5). The relatively limited trading of cereal residues in many sites implies only scant available data for residue market prices resulting in a wide array of relative residue to grain prices without any clear pattern.

The feed share of cereal residues appeared to be negatively associated with the density clusters (Fig. 3). Here we revisit the association by plotting the cereal residue use as feed against livestock density (Fig. 4). In Southern Africa's low-density sites, cereal residues represent an important feed resource mainly during the driest part of the year to the extent that most cereal residues produced are used as feed. Yet, as a component of total feed intake, residues are not as important as grazing (Fig. 2). Thus, shortages of residues perceived by farmers tend to be lower than in the medium-density and West African low-density sites. Nevertheless, Southern African farmers are constrained by the lack of alternative feed resources and low biomass production. In the medium-density and West African low-density sites, residues represent an important part of the feeding strategy. Besides feed use, farmers also use residues as fuel or construction as a result of the limited availability of alternative biomass resources, particularly in Ethiopia and West Africa. This limited availability of alternative resources increases the competition among residue uses in these mixed systems. All of this translates into marked periods of feed shortages in mediumdensity and West African sites. In high-density sites, despite the higher demand for feed and fuel, crop production is intensive 
Table 5

Characteristics of crop residue management in research sites.

\begin{tabular}{|c|c|c|c|c|c|c|c|c|c|c|c|c|}
\hline \multirow{2}{*}{$\begin{array}{l}\text { Density cluster } \\
\text { Site ID }\end{array}$} & \multicolumn{3}{|c|}{ High density } & \multicolumn{3}{|c|}{ Medium density } & \multicolumn{6}{|c|}{ Low density } \\
\hline & IN1 & $\mathrm{BD}$ & $\mathrm{KN}$ & ET2 & IN2 & ET1 & $\mathrm{ZW}$ & NG & $\mathrm{MZ}$ & NE2 & MW & NE1 \\
\hline \multicolumn{13}{|l|}{ Legume residues $^{\mathrm{b}}$} \\
\hline$\%$ sold & - & - & 0 & - & - & - & - & 42 & - & 27 & - & 51 \\
\hline$\%$ fed & - & - & 8 & - & - & - & - & 58 & - & 68 & - & 38 \\
\hline$\%$ other $^{\mathrm{c}}$ & - & - & 92 & - & - & - & - & 0 & - & 5 & - & 10 \\
\hline \multicolumn{13}{|l|}{ Increase use as: (\% villages) ${ }^{\mathrm{d}}$} \\
\hline Stall feed & 63 & 100 & 88 & 100 & 38 & 88 & 20 & 100 & 88 & 71 & - & 86 \\
\hline Stubble grazing & - & - & 38 & 67 & 0 & 25 & 50 & - & 50 & - & 75 & 88 \\
\hline Fuel & - & 71 & 100 & 100 & - & 63 & - & 88 & - & 57 & - & 100 \\
\hline Sold from home & 57 & 71 & - & - & - & 57 & - & 71 & - & - & - & 63 \\
\hline \multicolumn{13}{|l|}{ Left in the field (\% villages) } \\
\hline Decrease & 0 & 13 & 63 & 88 & 25 & 100 & 25 & - & 20 & - & 13 & 43 \\
\hline Increase & 63 & 88 & 38 & 0 & 0 & 0 & 75 & - & 40 & - & 75 & 57 \\
\hline Ratio crop residue:grain price & 0.8 & 0.1 & 0.1 & 0.1 & - & 0.3 & - & 0.7 & 0.6 & 0.4 & - & 0.5 \\
\hline Private ownership (\%) & 100 & 100 & 100 & 38 & 100 & 0 & 33 & - & 0 & - & 43 & - \\
\hline
\end{tabular}

and residue production substantial, and therefore, residues are more readily available year around. Although crop residues are an important part in the livestock diet-especially in South Asia-this amounts to less than $50 \%$ of residues produced. In high densitysites this allows crop residues to be left in the field and/or sold where markets have developed. In the case of Malawi, the high production of maize stover-aided by fertilizer subsidies-together with the lower level of livestock ownership among households, leads to a similar situation as in the high-density sites: high biomass production to cover the feed and fuel demands, and therefore, availability of some residues as mulch to improve soil quality.

\section{Discussion}

The aim of this paper was to obtain a better understanding of crop residue management in mixed crop-livestock systems across (sub)tropical Africa and Asia in view of the CA-mulching requirements. For the purposes of the present scoping study, the use of village surveys provides an efficient insight of farming processes and their context at a village level (Erenstein, 2010), despite not eliciting some of the variation within a village. Based on these comparative studies, it was possible to compare smallholder mixed systems and explore crop residue management practices along a gradient of human population and livestock density.

\subsection{Human population and livestock density and crop residue use}

Human population and livestock density in the research sites are related: i.e. high human population density coincides with high livestock density. Increasing densities typically implies an increasing demand for land, food and feed, inducing intensification of farming practices, as illustrated by the high-density sites in South Asia where agricultural inputs, irrigation and mechanisation are the highest. In the Kenyan case, although rainfall is high, the small size of farms limits agricultural production forcing both land intensification and livelihood diversification through a high income share from agricultural labour and off-farm employment (Tittonell et al., 2008; Iiyama et al., 2007b). Intensification of farming practices generally also results in higher biomass production and hence enhanced availability of residues and other feed resources. Thus, some residues can be used as livestock feed, mulch and/or fuel; although trade-offs also depend on the type of residue and market conditions. Despite such a relatively positive scenario, feed shortages still exist in high-density sites, as well as poverty, inequity and environmental degradation, presenting key challenges to the development of smallholder farms in these sites (Moebius-Clune et al., 2011; Ralevic et al., 2010; Sharma et al., 2010).

In medium-density sites, human population and livestock densities are lower, while agricultural production is less intensive and alternative resources are scarce (e.g. feed, fuel and construction material). In India-2 this is partially compensated by remittances, while in the Ethiopian sites farmers still largely rely on crop and livestock production. This results in high competition for residue use, along with an overall scarcity of residue biomass. This leads to most of the residues being taken from the field to cover the needs for feed, fuel and construction. Even then, feed shortages appear the highest in these medium livestock density sites. The already precarious situation in these sites is further aggravated by increasing human population and livestock numbers, food insecurity, low market access/participation and land degradation (see also Spielman et al., 2011; Dhaka et al., 2011).

In low-density sites, human population and livestock densities are by definition relatively low, albeit that croplands continue to expand and thus reduce communal grazing resources, particularly in West Africa (Gaiser et al., 2011; Hiernaux et al., 2009; Powell et al., 2004). Our low-density sites are all semi-arid and their aridity, poor soil fertility and poor access to farming inputs result in low crop productivity (Powell et al., 2004). Feed from expanding croplands cannot compensate for the reduction of grazing resources, and pressure on residues is therefore increasing, especially in the West African sites where most of the communal land has disappeared or is largely degraded (Abdoulaye and Lowenberg-DeBoer, 2000; Sibanda et al., 2011). For legume residues, their high value as feed and the increasing demands from livestock feed have created localized residue markets in West Africa (Singh and Ajeigbe, 2007). In Southern Africa, limited access to legume seed and farmers' preferences for cereals as staple foods contribute to the limited availability of legumes and their residues (Mazvimavi et al., 2010). Where available, farmers appreciate legume residues particularly for feeding small stock (Homann-Kee Tui et al., 2007). The reduced rangelands and lack of alternative feed resources-especially during the long dry season-lead to the removal of most of the residues from the fields (Ben Salem and Smith, 2008; Rufino et al., 2011). In contrast, in Malawi, relatively higher rainfall, fertilizer subsidy programmes and low livestock numbers allow the use of residues as feed and mulch. 


\subsection{Mulching of crop residues}

The assessment of current crop residue management gives a better insight into the challenges and opportunities of CA-based mulching with crop residues in different mixed crop-livestock systems. This study thereby supports the argument of Giller et al. (2009) that adoption of CA-based mulching is troublesome in farming systems with low biomass production. Our results suggest that only mixed systems with high biomass production compared to the feed demands (i.e. livestock density) had enough surplus residues to mulch. Such biomass production needs to be considerable in sites where livestock are an important part of the livelihood of smallholder farmers as in the case of the high-density sites. Nevertheless, complementary changes in farming practices (e.g. reducing tillage and residue burning) in these sites are still needed to actually retain surplus residues as mulch in farmer fields (Erenstein, 2011; Bijay-Singh et al., 2008). In medium- and low-density sites, not only biomass production, but also ownership of residues and livestock access to the fields after harvesting represents major challenges to more widespread use of mulching (see also Mazvimavi et al., 2010; Nyssen et al., 2011; Sibanda et al., 2011). Additionally, where markets develop for crop residues, this creates additional pressure and obvious opportunity costs, even for households with no livestock or an excess of residue production.

Our assessment also indicates that the adoption of mulching might be less problematic for some mixed systems than for others (Erenstein, 2003). Farmers in sites with high biomass production compared to demands on residues for feed, fuel or construction are more likely to be able to allocate extra residues for mulching practices. In sites where agricultural production or alternative resources are unable to meet the growing demands for crop residues caused by increasing human and livestock populations, the introduction of mulching practices appears particularly challenging. Therefore although CA-based mulching has the potential to improve agricultural production in smallholder mixed farmers, its successful introduction may require levels of biomass production which are often lacking in the poor and drier areas of (sub)tropical Africa and Asia (Giller et al., 2009).

The results of this study also reiterate earlier statements that there is no silver bullet for creating more sustainable farming systems (Erenstein, 2002; Giller et al., 2011a). In the case of CA in mixed systems in Sub-Sahara Africa and South Asia, several challenges remain:

1. Soil cover challenges: Although general patterns can be distinguished, trade-offs on residue use are both site and crop specific. As shown in the present paper, human population and livestock density, cropping intensity, access to alternative feed sources, land and markets, and non-agricultural income represent socioeconomic factors to be included in the analysis of mulching options for smallholder farmers. Furthermore, alleviating competing residue demands often needs to be complemented with additional management practices to ensure surplus residue are actually retained as mulch/soil cover after crop establishment (Erenstein, 2002).

2. Legume rotation challenges: Crop rotation, particularly with legumes is one of the CA principles. Legumes are of particular interest in view of being a potential organic source of nitrogen to enhance soil health and quality (FAO, 2001a,b; Kassam et al., 2010). Still, such potential contribution of legumes is challenged by the often relatively high value of the above-ground legume biomass as feed and being a potential income source for farmers (Singh and Ajeigbe, 2007).

3. Tillage reduction challenges: Tillage either by animal or tractor is widely practice across the research sites, indicating that major changes in farming practices are needed to reduce tillage practices (Wall, 2007). Additionally, reducing tillage leads to challenges in combating weeds (Mupangwa, 2009; Erenstein, 2002). Although herbicides can play an important role, their use in particularly medium- and low-density clusters is often constrained by their limited availability and cost and cash flow problems. Herbicide use is often less of an option for female and/or poor subsistence farmers in remote areas (Mazvimavi and Twomlow, 2009), where even fertilizer and seed availability is a challenge. Reduced tillage may also increase the weeding burden for women, particularly in Sub-Sahara Africa (Giller et al., 2009).

\subsection{Implications for policy, research and development}

From a CA perspective it is encouraging to note that high livestock densities and mulching are not necessarily antagonistic-provided adequate biomass is produced. More sobering and perhaps somewhat surprising is the realization that even in low livestock density areas with what appear as ample additional feed resources the feed pressure on crop residues can still be high. This reiterates the importance of both demand and supply factors whenever considering crop residue trade-offs and targeting CA-based mulching. Solutions towards more sustainable farming systems require research and development organizations to incorporate more closely the local biophysical and socio-economic specificities of farming (Erenstein, 2002; Giller et al., 2011b). Even the diversity within sites and villages, and the diversity of plots within the farm need to be considered to better target solutions (Tittonell et al., 2010; Guto et al., 2011).

This research reiterates that crop and livestock are integral components of most smallholder livelihoods in Sub-Sahara Africa and South Asia, and therefore, technologies and approaches need to include both crops and livestock to better sustain agricultural production (Fresco and Steinfeld, 1998; Renard, 1997). In sites where crop and livestock production represent a marginal income share, farmers might face less agricultural risk, but also less interest to develop more sustainable farming practices. As CA practices have so far been more widely adopted in large-scale farms in the Americas and Oceania (Kassam et al., 2010), it seems likely that such practices will be more easily introduced in the more intensive areas in (sub)tropical Africa and Asia. Adapting economical and viable CA options to suit the needs of poor smallholders particularly in drier environments thereby remains a challenge that CA advocates need to continue to address (Giller et al., 2011a). Promising in this respect is that mulching typically conserves soil and water and thereby potentially can boost and stabilize crop productivity in water constrained settings (Erenstein, 2003; Kumar and Goh, 1999)-thereby alleviating future trade-offs.

The present study is scoping by nature and did not intend to provide definite answers. Instead it does provide additional insights in where and how best to target CA-based mulching interventions and some of the complementary research and development needed. In particular, our study flags the important complementary role of agricultural intensification. It thereby suggests that introducing mulching is relatively easier in already intensified agricultural systems with ample annual biomass production sufficient to meet the various demands including the retention of some crop residues as mulch. In fact, in such intensive systems the introduction of CA revolves around adapting viable management options so as to handle and retain surplus crop residues as mulch; whereas in extensive systems it now appears more a question of crop residue protection so as to meet minimal levels of retention. However, at the same time our study suggests that by enabling agricultural intensification, introduction of CA-based mulching practices would become relatively easier and more viable. 
Our low-density sites tend to be extensive low input-low output systems with ongoing population increases inducing further crop area expansion-but not necessarily intensification. The medium density sites too remain relatively extensive-but with relatively less alternative feed sources and thereby pressing feed shortages. The challenge thereby becomes how to viably intensify these systems to lift them to more viable yield and biomass productivity levels. First, this calls for complementary crop intensification technologies such as appropriate improved varieties, external input use and appropriate crop management, including options to increase the efficient use of water wherever water availability constrains productivity. Increased use of chemical fertilizers is a particularly promising way to enhance yields and biomass production (Palm et al., 2001; Giller et al., 2011a). Second, viable agricultural intensification calls for an enabling environment through appropriate policies and developed markets and value chains. Indeed, whereas chemical fertilizers now long exist, their use is limited and variously constrained in mixed smallholders systems, particularly in medium-low density areas in Sub-Sahara Africa (Morris et al., 2007). Despite renewed discussions on providing subsides to smallholder farmers to purchase fertilizer and seed, such as in Malawi, subsidy programmes can bias crop choice (Chibwana et al., 2012) while facing political challenges (Banful, 2011). Third, system intensification can be further complemented by the development of alternative sources of feed, fuel and construction material. For instance, research and development could enhance forage production and increase feed quality through dual purpose crops (Blümmel et al., 2003; Lenné et al., 2003; Ralevic et al., 2010). In the end, overall economic development is also likely to reduce competing residue demands by providing alternative and more efficient substitutes.

\section{Conclusions}

Smallholder mixed systems in (sub)tropical Africa and Asia span a wide and diverse gradient from low density (human population and livestock) extensive systems to high density intensive systems, but with crop residues being an important source of livestock feed across the board. In intensive systems the biomass productivity is such that only a share of crop residues produced is used as livestock feed despite high livestock densities-leaving substantial surplus residues some of which are already retained in the fields. The extensive systems in contrast present a precarious situation with limited amounts of crop residues being intensively used as livestock feed during the long dry season and despite the availability of alternative feed sources. Introduction of CA-based mulching in these mixed systems thereby faces diverse challenges and opportunities. Our study thereby highlights the important complementary role of agricultural intensification-first as the intensification gradient helps better target and adapt CA-based mulching interventions; and second as intensification enables the introduction of CA-based mulching practices.

\section{Acknowledgements}

This research received financial support from and is part of the System-wide Livestock Programme (http://www.vslp.org/), of the Consultative Group of International Agricultural Research (CGIAR) which aims to build and enhance links between crop-, agroforestry, natural resource-, policy- and livestock-oriented research and development. We would like to acknowledge those who supported the collection and correction of the data, especially Romain Frelat, Kindu Mekonnen, Nkululeko Mpofu, Abdou Salla and Braja Swain and the reviewers for their constructive comments. The views expressed in this paper are the authors' and do not necessarily reflect the views of the System-wide Livestock Programme or the authors' institutions.

\section{References}

Abdoulaye, T., Lowenberg-DeBoer, J., 2000. Intensification of Sahelian Farming systems: evidence from Niger. Agric. Syst. 64, 67-81.

Banful, A.B., 2011. Old problems in the new solutions? Politically motivated allocation of program benefits and the new fertilizer subsidies. World Dev. 39, 1166-1176.

Ben Salem, H., Smith, T., 2008. Feeding strategies to increase small ruminant production in dry environments. Small Rumin. Res. 77, 174-194.

Bijay-Singh Shan, Y.H., Johnson-Beebout, S.E., Yadvinder-Singh Buresh, R.J., 2008. Crop residue management for lowland rice-based cropping systems in Asia. Adv. Agron. 94, 117-199.

Blümmel, M., Zerbini, E., Reddy, B.V.S., Hash, C.T., Bidinger, F., Ravi, D., 2003. Improving the production and utilization of sorghum and pearl millet as livestock feed: methodological problems and possible solutions. Field Crops Res. 84, 123-142.

Chibwana, C., Fisher, M., Shively, G., 2012. Cropland Allocation Effects of Agricultural Input Subsidies in Malawi. World Dev. 40, 124-133.

Christiaensen, L., Tollens, E., Ezedinma, C., 1995. Development patterns under population pressure. Agricultural development and the cassava-livestock interaction in smallholder farming systems in Sub-Saharan Africa. Agric. Syst. 48, 51-72.

Dhaka, B.L., Chayal, K., Poonia, M.K., 2011. Identification of constraints limiting the productivity of livestock and strategies for its improvement in Bundi district of Rajasthan. Indian J. Anim. Sci. 81, 94-96.

Erenstein, O., 2002. Crop residue mulching in tropical and semi-tropical countries. An evaluation of residue availability and other technological implications. Soil Till. Res. 67, 115-133.

Erenstein, O., 2003. Smallholder conservation farming in the tropics and sub-tropics: a guide to the development and dissemination of mulching with crop residues and cover crops. Agric. Ecosyst. Environ. 100, 17-37.

Erenstein, O., 2010. Village surveys for technology uptake monitoring: case of tillage dynamics in the Trans-Gangetic Plains. Exp. Agric. 46, 277-292.

Erenstein, O., 2011. Cropping systems and crop residue management in the TransGangetic Plains: issues and challenges for conservation agriculture from village surveys. Agric. Syst. 104, 54-62.

Erenstein, O., Samaddar, A., Teufel, N., Blümmel, M., 2011. The paradox of limited maize stover use in India's smallholder crop-livestock systems. Exp. Agric. 47, 677-704.

FAO, 2001a. Mixed Crop-Livestock Farming. FAO, Rome.

FAO, 2001b. Conservation Agriculture: Case Studies in Latin America and Africa. FAO, Rome.

FAO, 2009. Scaling up Conservation Agriculture in Africa: Strategy and Approaches. FAO, Addis Ababa.

Fafchamps, M., Udry, C.R., Czukas, K., 1998. Drought and saving in West Africa: are livestock a buffer stock? J. Dev. Econ. 55, 273-305.

Fresco, L.O., Steinfeld, H., 1998. A food security perspective to livestock and the environment. Livestock and the environment. In: Nell, A.J. (Ed.), Proceedings of the International Conference on Livestock and the Environment. Ede/Wageningen, Netherlands, June 16-20, 1997. FAO, Rome, pp. 5-12.

Gaiser, T., Judex, M., Igué, A.M., Paeth, H., Hiepe, C., 2011. Future productivity of fallow systems in Sub-Saharan Africa: is the effect of demographic pressure and fallow reduction more significant than climate change? Agr. Forest Meteorol. $151,1120-1130$.

Giller, K.E., Corbeels, M., Nyamangara, J., Triomphe, B., Affholder, F., Scopel, E., Tittonell, P., 2011a. A research agenda to explore the role of conservation agriculture in African smallholder farming systems. Field Crops Res. 124, 468-472.

Giller, K.E., Tittonell, P., Rufino, M.C., van Wijk, M.T., Zingore, S., Mapfumo, P., AdjeiNsiah, S., Herrero, M., Chikowo, R., Corbeels, M., Rowe, E.C., Baijukya, F., Mwijage, A., Smith, J., Yeboah, E., van der Burg, W.J., Sanogo, O.M., Misiko, M., de Ridder, N., Karanja, S., Kaizzi, C., K'ungu, J., Mwale, M., Nwaga, D., Pacini, C., Vanlauwe, B., 2011b. Communicating complexity: Integrated assessment of trade-offs concerning soil fertility management within African farming systems to support innovation and development. Agric. Syst. 104, 191-203.

Giller, K.E., Witter, E., Corbeels, M., Tittonell, P., 2009. Conservation agriculture and smallholder farming in Africa: the heretics' view. Field Crops Res. 114, 23-34.

Govaerts, B., Verhulst, N., Castellanos-Navarrete, A., Sayre, K.D., Dixon, J., Dendooven, L., 2009. Conservation agriculture and soil carbon sequestration: between myth and farmer reality. Crit. Rev. Plant Sci. 28, 97-122.

Guto, S.N., Pypers, P., Vanlauwe, B., de Ridder, N., Giller, K.E., 2011. Socio-ecological niches for minimum tillage and crop-residue retention in continuous maize cropping systems in smallholder farms of central Kenya. Agron. J. 103, 644-654.

Herrero, M., Thornton, P.K., Notenbaert, A.M., Wood, S., Msangi, S., Freeman, H.A., Bossio, D., Dixon, J., Peters, M., van de Steeg, J., Lynam, J., Rao, P.P., Macmillan, S., Gerard, B., McDermott, J., Seré, C., Rosegrant, M., 2010. Smart investments in sustainable food production: revisiting mixed crop-livestock systems. Science $327,822-825$.

Hiernaux, P., Ayantunde, A., Kalilou, A., Mougin, E., Gérard, B., Baup, F., Grippa, M., Djaby, B., 2009. Trends in productivity of crops, fallow and rangelands in Southwest Niger: impact of land use, management and variable rainfall. J. Hydrol. 375 65-77.

Hobbs, P.R., Sayre, K., Gupta, R., 2008. The role of conservation agriculture in sustainable agriculture. Phil. Trans. Royal. Soc. B 363, 543-555. 
Hoddinott, J., 2006. Shocks and their consequences across and within households in rural Zimbabwe. J. Dev. Stud. 42, 301-321.

Homann-Kee Tui, S., van Rooyen, A., Moyo, T., Nengomahsa, Z., 2007. Goat Production and Marketing: Baseline Information for Semi-arid Zimbabwe. ICRISAT, Bulawayo.

Iiyama, M., Kaitibie, S., Kariuki, P., Morimoto, Y., 2007a. The status of crop-livestock systems and evolution toward integration. Ann. Arid Zone 46, 301-323.

Iiyama, M., Maitima, J., Kariuki, P., 2007b. Crop-livestock diversification patterns in relation to income and manure use: a case study from a Rift Valley Community, Kenya. Afr. J. Agric. Res. 2, 58-66.

Kassam, A., Friedrich, T., Shaxson, F., Pretty, J., 2010. The spread of Conservation Agriculture: justification, sustainability and uptake. Int. J. Agric. Sust. 7, 292-320.

Knowler, D., Bradshaw, B., 2007. Farmers' adoption of conservation agriculture: a review and synthesis of recent research. Food Policy 32, 25-48.

Kumar, K., Goh, K.M., 1999. Crop residues and management practices effects on soil quality, soil nitrogen dynamics, crop yield, and nitrogen recovery. Adv. Agron. 68, 197-319.

Lenné, J.M., Fernandez-Rivera, S., Blümmel, M., 2003. Approaches to improve the utilization of food-feed crops - synthesis. Field Crops Res. 84, 213-222.

Mazvimavi, K., Ndlovu, P.V., Nyathi, P., Minde, I., 2010. Conservation agriculture practices and adoption by smallholder farmers in Zimbabwe. In: AAAE 3rd Conference/AEASA 48th Conference, Cape Town, South Africa, AAAE, South Africa, September 19-23.

Mazvimavi, K., Twomlow, S., 2009. Socioeconomic and institutional factors influencing adoption of conservation farming by vulnerable households in Zimbabwe. Agric. Syst. 101, 20-29.

McIntire, J., Bourzat, D., Pingali, P., 1992. Crop-Livestock Interactions in Sub-Saharan Africa. World Bank, Washington, D.C.

McIntire, J., Gryseels, G., 1987. Crop-livestock interactions in Sub-Saharan Africa and their implication for farming systems research. Exp. Agric. 23, 235-243.

Moebius-Clune, B.N., van Es, H.M., Idowu, O.J., Schindelbeck, R.R., Kimetu, J.M., Ngoze, S., Lehmann, J., Kinyangi, J.M., 2011. Long-term soil quality degradation along a cultivation chronosequence in western Kenya. Agric. Ecosyst. Environ. 141, 86-99.

Moll, H.A.J., 2005. Costs and benefits of livestock systems and the role of market and nonmarket relationships. Agric. Econ. 32, 181-193.

Morris, M., Kelly, V.A., Kopicki, R.J., Byerlee, D., 2007. Fertilizer Use in African Agriculture: Lessons Learned and Good Practice Guidelines. World Bank, Washington, D.C.

Mupangwa, W., 2009. Water and nitrogen management for risk mitigation in semiarid cropping systems. PhD thesis. University of the Free State, South Africa.
Nyssen, J., Govaerts, B., Araya, T., Cornelis, W.M., Bauer, H., Haile, M., Sayre, K., Deckers, J., 2011. The use of the marasha ard plough for conservation agriculture in northern Ethiopia. In: Lichtfouse, E., Hamelin, M., Navarrete, M., Debaeke, P. (Eds.), Sustainable Agriculture, vol. 2. Springer, Netherlands, pp. 295-308.

Palm, C.A., Gachengo, C.N., Delve, R.J., Cadisch, G., Giller, K.E., 2001. Organic inputs for soil fertility management in tropical agroecosystems: application of an organic resource database. Agric. Ecosyst. Environ. 83, 27-42.

Powell, J.M., Pearson, R.A., Hiernaux, P.H., 2004. Crop-livestock interactions in the West African drylands. Agron. J. 96, 469-483.

Ralevic, P., Patil, S.G., vanLoon, G., 2010. Integrated agriculture production systems for meeting household food, fodder and fuel security. J. Sust. Agric. 34 878-906.

Renard, C., 1997. Crop Residues in Sustainable Mixed Crops/Livestock Farming Systems. CAB International, New York.

Rufino, M.C., Dury, J., Tittonell, P., van Wijk, M.T., Herrero, M., Zingore, S., Mapfumo P., Giller, K.E., 2011. Competing use of organic resources village-level interactions between farm types and climate variability in a communal area of NE Zimbabwe. Agric. Syst. 104, 175-190.

Sharma, B., Amarasinghe, U., Xueliang, C., de Condappa, D., Shah, T., Mukherji, A. Bharati, L., Ambili, G., Qureshi, A., Pant, D., Xenarios, S., Singh, R., Smakhtin, V. 2010. The Indus and the Ganges: river basins under extreme pressure. Water Int. 35, 493-521.

Sibanda, A., Homann-Kee Tui, S., van Rooyen, A., Dimes, J., Nkomboni, D., Sisito G., 2011. Understanding community perceptions of land use changes in the rangelands, Zimbabwe. Exp. Agric. 47, 153-168.

Singh, B.B., Ajeigbe, H., 2007. Improved cowpea-cereals-based cropping systems for household food security and poverty reduction in West Africa. J. Crop Improv. 19, 157-172.

Spielman, D., Davis, K., Negash, M., Ayele, G., 2011. Rural innovation systems and networks: findings from a study of Ethiopian smallholders. Agric. Human Values $28,195-212$.

Tittonell, P., Corbeels, M., van Wijk, M.T., Vanlauwe, B., Giller, K.E., 2008. Combining organic and mineral fertilizers for integrated soil fertility management in smallholder farming systems of Kenya: explorations using the crop-soil model FIELD. Agron. J. 100, 1511-1526.

Tittonell, P., Muriuki, A., Shepherd, K.D., Mugendi, D., Kaizzi, K.C., Okeyo, J., Ver chot, L., Coe, R., Vanlauwe, B., 2010. The diversity of rural livelihoods and their influence on soil fertility in agricultural systems of East Africa - a typology of smallholder farms. Agric. Syst. 103, 83-97.

Wall, P.C., 2007. Tailoring conservation agriculture to the needs of small farmers in developing countries: an analysis of issues. J. Crop Improv. 19, 137-155. 